\title{
University-industry cooperation for encouragement of graduating employability - methodology for evaluation
}

\author{
Daniela YORDANOVA \\ University of Ruse "Angel Kanchev", Ruse, Bulgaria \\ dyordanova@uni-ruse.bg
}

\begin{abstract}
Employability of graduating students is a main precondition for successful university to work transition. Discrepancies on the labour market in terms of demand and supply of highly qualified specialists, increasing requirements and expectations of recently university graduates towards their future jobs, high speed of technological changes resulting in new jobs for which educations is lagging behind and increasing demand for well-developed transferable skills are some of the main challenges which universities are facing nowadays. Thus, their main priorities shall stress on collaboration that is more effective with industrial companies, resulting in contemporary curricula and development and implementation of new forms of cooperation for encouragement of graduating students' employability. There are some good practices in Bulgaria for common initiatives leading to better professional orientation and further job placing but there is a lack of overall strategic approach in this field. Therefore, there is a necessity of identification and introduction of new forms of cooperation, which will boost partnership and could provide the labour market with more adequate specialists, matching employers' recent requirements. The purpose of the paper is to provide a methodology of evaluation of problems in university-industry cooperation for encouragement of graduating students' employability.The main elements of research of cooperation between universities and industry in Bulgaria include (1) description of possible forms of cooperation, (2) evaluation of industry attitudes for cooperation based on 4 criteria - importance, application, interest for participation and awareness of the forms, (3) comparison of opinions of industry and universities in Bulgaria.
\end{abstract}

Keywords: university - industry cooperation, employability, university to work transition, industry attitudes for cooperation, forms of cooperation, methodology.

\section{Introduction}

The short period of transition from university to work and job placement, corresponding to graduates' specialty with satisfying salary rate are some of main criteria for evaluation of quality of university education (NEEA, 2016).Employers are looking for people with adequate and up to date qualification, including good practical experience and well developed soft skills (Ghinea \& Moroianu, 2016). Graduates, representing Millennials generation demonstrate high expectation for level of salary, work conditions, package of social incentives, provided by employers and guaranteed possibility for work - life balance. Series of international studies of Deloitte (Deloitte, 2013, Deloitte, 2015) shows that requirement of best graduates in some of the best universities in Europe are so high that most of the employers fail to respond to them and it appear that they cannot afford best graduates. Acting in such environment universities are facing challenge to provide better education fitting to industry requirements in situation of lack of information for future labour market needs, because of two reasons. First, the fast changes in technologies created situation in which after their graduation students will work at occupation that still do not exist. Second, the changes in education system in general can be introduced slowly, because the procedure for introduction of changes in curricula for a specialty requires long 
administrative path and the period between the entrance and exit of students from educational system is long.

All those issues raises the question how university can provide students with better education, adequate to the industry needs. The solution is attraction of stakeholders in education process and increase of their motivation for cooperation. They include university, as provider of knowledge and skills, representatives of industry as future employers, students, who shall obtain high employability and government as actor, providing favourable environment for cooperation between other three parties (Fig. 1).

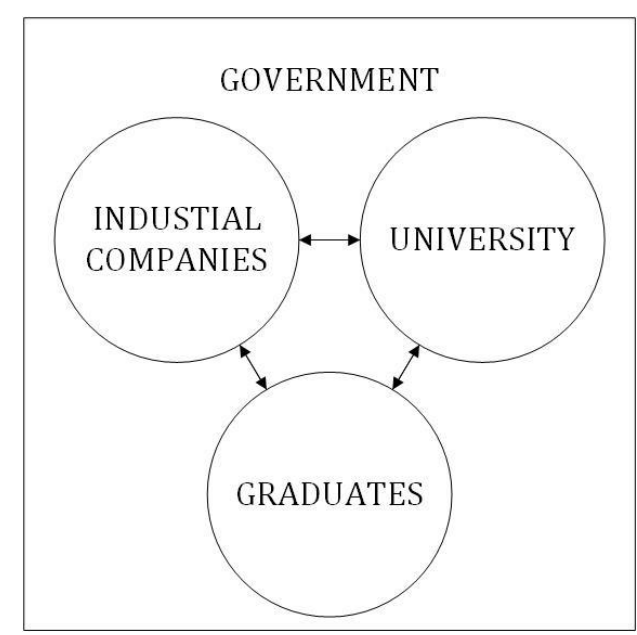

Figure 1. Triangle of stakeholders for encouragement of graduating students' employability

PICBE |1049

Source: adaptation on Yordanova, D. (2013)

Cooperation between universities and business for better response to labour market needs is a possibility for fast adaptation of educational system. From one side companies or institutions provide inputs for strategic decisions in collaboration process and support "the teaching-evaluation style". From the other side universities are developing strategies for attraction and involvement of business through cooperation and thus they improve existing curricula in correspondence to market labor needs (Dima \& Ghinea, 2016). On the other hand, business is particularly interested to be actively involved in the university life to reduce cost with selection, training and recruitment. The practice in different countries varies depending on historical preconditions, values and attitudes, economic state and legislative framework. In most developed economies in EU, where the level of unemployment is low the active role for supporting cooperation is held by employers. They are looking for better employees during the study period and provide internship positions and incentives for students. In less developed economies the leading role belongs to educational institutions, who aim to stimulate industrial companies to become more active in communication and cooperation. The case of Bulgaria includes some specifics. Following the declining number of graduating in system of secondary education and huge scale of discrepancies at the labour market Bulgarian government introduced legislative change, bounding the quality of provided education and it compliance with labour market needs with the subsidy, provided by government for support of education in state universities 
(DCM №328/30-11-2015). This forced universities to become more active in cooperation with industrial companies for search of better solution for employability encouragement and effective transition to work. This reveals the necessity of development and introduction of new forms of cooperation.

Many papers discuss the role of educational institutions for university to work transition (Herrington and Herrington, 2004,Ferrer - Balaset al., 2009, Balta et al., 2012), business requirements for university graduates skills and knowledge (Rumberger, 1984, Teichler, 2007, Dimitrova, 2012) and compliance of university education with labour market demands (Afonsoet al., 2012).Despite of that there is a little research on opinion of employers about their interest to be part of cooperation with universities for boosting the employability of graduating students. There are some good practices in Bulgaria for common initiatives leading to better professional orientation and further job placing but there is a lack of overall strategic approach in this field. Therefore, there is a necessity of identification and introduction of new forms of cooperation, which will boost partnership and could provide the labour market with more adequate specialists, matching industry's recent requirements.

The purpose of the paper is to provide a methodology of evaluation of problems in university-industry cooperation for encouragement of graduates' employability. The main elements of research of cooperation between universities and industry in Bulgaria for encouragement of graduates' employability include (1) definition of possible forms of cooperation, (2) evaluation of industry attitudes for cooperation based on 4 criteria importance, application, interest for participation and awareness of the forms, (3) comparison of opinions of industry and universities in Bulgaria.

\section{Literature review}

Graduates' employability is main prerequisite for successful first job, consisting of "business specific issues (hard business-related knowledge and skills), interpersonal competencies (soft business-related skills) and work experience and work-based learning" (Andrews and Higson, 2008).

Changes in society force the universities to reconsider new strategies and approaches for development of people who will learn through their whole entire life (McLoughlin, C., Luca, J., 2002) and to respond to labour market requirements. High education shall provide professional knowledge and skills together with transferable ones, necessary for the occupation they study for (Allan, 1996, Atkins, 1995, Heckman \&Kautz, 2012).Oliver and McLoughlin(2000) use the term generic skills to describe the transferable skills that are considered to be essential life skills for people both in and out of the workforce. Generic skills relate to critical thinking, inquiry and a capacity for lifelong learning and by their very nature are difficult to teach through formal instruction. Bennett, Dunne and Carre (1999) propose classification of transferable skills, related with individual managerial abilities - self-management, management of others, management of tasks and management of information. Development of all required skills in educational system is challenging because the pedagogical approaches are not adapted for development of professional expertise, due to curricula content, teaching methods and evaluation forms. 
Encouragement of employability requires introduction of changes in educational system, which can be effective only if meet the recent need of business. Ghinea et al. (2017) points out that element leading to excellence and sustainable convergence is the particular application of the higher education process to the requirements of the respective labour market. Company competitiveness depends on employability of its human resources, which can be a major stimulus for business to join the initiatives.

PICBE $\mid 1051$

Industrial companies' benefits from collaboration with universities are in few directions: provision of qualified personnel, increase of personnel's qualification, provision of expertise through direct enrolment of researchers in company's activities (including job placement), R\&TD, consultancies and technology transfer, implementation of joint project initiatives etc.

Universities' benefits from other side can be described as: receiving of funding from business for education of personnel, establishment of corporative and research universities, provision of funding for implementation of important projects, attendance of practitioners in educational process, provision of access to laboratories and equipment for realization of research and development activities, establishment of joint ventures, business incubators, technology transfer centres. Kanev (2006) defines the process of common pervasion of education and business "educational outsourcing", which put in practice lifelong learning.

The relationship between stakeholder and influence they can have on employability and first job placement of graduating students can be described in a conceptual model.

Graduating are facing different obstacles searching their first job, which can be explored in two perspectives - obstacles, resulting from environment (external factors) and from personal characteristics of the individual (internal factors). For definition of external factors, influencing on transition from education to work can be applied STEP analysis, which divide the external for each individual environment to social, technological, economic and political components and factors. Main trends describing external environment includes discrepancies on the labour market, over education, migration processes, gender equality, change in ethnic structure of societies, changes in attitudes of generations entering labour market, trends, level of family incomes, average salary in the regions, legislation of the country, technological changes providing possibilities to work all over the world. The knowledge, education, skills, contacts with other people and heritage are part of each person. That is why the internal factors can be defined as 1) human capital - including obtained knowledge, skills, existing motivation, needs and talents, 2) social capital, which includes all networks, created by individual and own ability to create them and 3) cultural capital, relating with values, self-evaluation, inherited culture, moral, expectation and attitudes (Figure 2).

Based on chosen definitions we can create a conceptual theoretical model for management of transition from university to professional realization of graduates and encouragement of their professional realization and employability. The model presents the role of university who can encourage employability and transition to work of students by influencing development of internal factors in cooperation with industrial companies, implementing activities, based on incentive governmental policy within the environment, in which all agents operate. 
Components of external environment can be evaluated at regional, national or global level. It is important to apply complex approach, because young people are ready to move to more developed region for exploring better employment opportunities and quality of life and tend to prefer emigration if better possibilities are not provided in their own country. Labour market institutions operate at national level while formulating policies and measures, but unemployment specifics have predominantly regional character. The local labour markets are influenced by world trends like globalization, huge migration flows between countries, fast penetration of new technologies, economic crises and political relationships between countries.

Therefore there is a need of unified approach for encouragement of employability and professional realization of graduates, which can be applied at regional level, which can be applicable also at national scale and shall allow to be included in national employment policy.

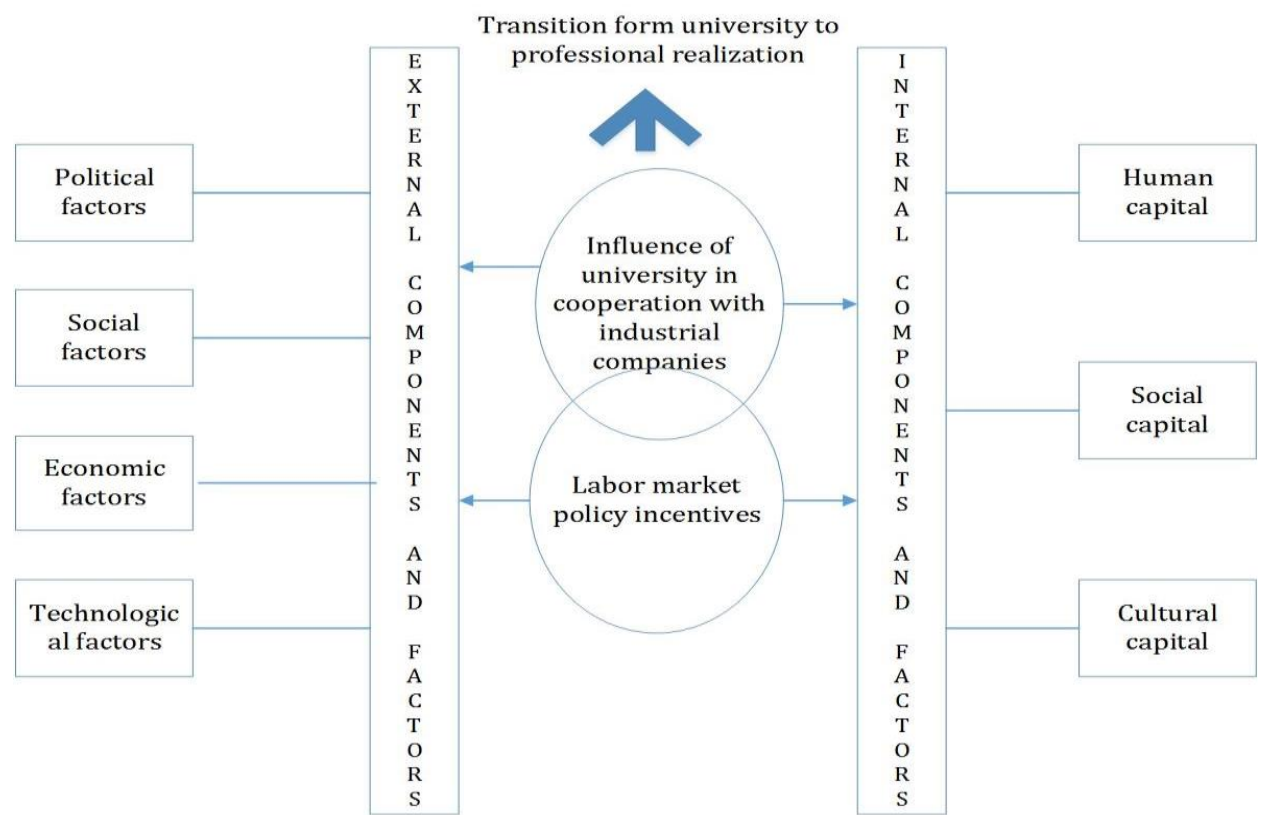

Figure 2. Conceptual model for management of transition from university to professional realization of graduates

\section{Limitations of the model}

The model is dynamic, and some factors of external environment may lose their influence on account of others.

The environment is dynamic and it is possible that some new factor appear and some of already existing can drop out.

With certain modifications the model can be applied for evaluation of factors influencing school to work transition at any stage of education.

It is accepted that during the time in universitythe educational institution is responsible for development of individual human capital, including knowledge and 
practical experience, while for the accumulation of social capital including competences and skills main influence comes from family and friends.

Development of individual internal environment is main prerequisite for successful professional realization. The more developed are its component the better level of employability an individual possess. The person itself, the family, social contacts, education system and many more factors are influencing on that process and the force of each of them is different and can vary. Educational institutions are perceived as main factor for development of knowledge and skills but their roles for building up personal characteristics- soft skills and competencies is highly underestimated.

Educational institutions can have crucial role for development of internal environment components, although they are not widely accepted as leading for shaping values, attitudes, expectations and motivation for work, abilities for development of social capital and soft skills. (Heckman, J. J., \&Kautz, T., 2012).

Cooperation between university and industry has a leading role in the proposed conceptual model for encouragement of transition from university to work through employability. The model can be used for explanation of role and influence possibilities of each components from external and internal environment. Each external factor can be influenced by any internal one. For instance if the university provides education with good quality the short period of transition to firs job will depend on demand on labour market and soft skills of the individual. The main obstacle appears to be lack of work experience.

The model can be used also for evaluation of entrepreneurial readiness and desire of young people to start their own business and support which universities can provide in this direction. Key elements of external environment will be the existence of financial mechanisms for support of start-ups, availability of business supporting entities like business incubators, business angels and business management knowledge (which is lacking among students with engineering background), universities developed practices for training and support through university business incubators, provision of loans bearing no interest, co-funding of student's business ideas, consultancies, mentorship, assistance for establishment of relationships with business partners, marketing of students' companies and their products.

\section{Methodology}

Which shall be the most appropriate approach to boost university - industry partnership? Different countries will apply different models for achievement of this purpose. In Bulgaria the main problems consist of low interest of employers to collaborate with institutions of tertiary education due to weak connection with research centres, lack of long range planning, including planning of human resources needs, insufficient knowledge of opportunities for cooperation and benefit from it and specific values and attitudes.

The obstacles and possibilities in front of university - industry partnership can be evaluated through enquiry, focused on industrial companies opinion. The research is based on already implemented similar research among representatives of universities in Bulgaria for evaluation of evaluation of problems of cooperation between universities and industrial companies for encouragement of employability of graduating students. The research was conducted in 2013-14 from team of University of Ruse (Naydenovet al., 2016) due to the 
method of expert evaluations by use of questionnaire and semi-structured interview. Enquiry spread over 8 universities among these, providing education in professional field "Administration and management" and "General engineering".35 expert were included in inquiry. They were at positions of vice rector, vice dean of faculty and manager of department from units, providing education in targeted professional fields and one professor, responsible for management of education in department.

PICBE $\mid 1054$

Questionnaire consists of two groups of questions - first aims to provide general evaluation of state of cooperation between two groups and second part, consisting 22 questions, aiming to evaluate 11 forms of cooperation using 2 criteria - importance and application in practice. The forms are chosen in correspondence to well spread practices among universities, literature review and experts' opinions.

Forms of cooperation between universities and industrial companies for encouragement of employability of graduating students relate to attendance of employers in following joint initiatives:

(1) Participation of business managers or representatives in the University's decision making processes in relation to curricula content and training programmes, requirements of university graduates in the labour market, etc.

(2) Joint formulation by the University and business representatives of the graduates' knowledge requirements as regards the enterprise world, business processes and management, operational competences, etc.

(3) Joint formulation by the University and business representatives of the graduate's requirements as regards basic managerial and social competences (such as motivation and teamwork, communication and conflict resolution);

(4) Information to graduate students by enterprise managers on business developments and trends, as well as the evolution, strategies, problems and possible solutions in their own companies.

(5)Design along with enterprises, and implementation by the University, of a system of criteria and standards for early identification of the students' talents and guide them to collaborating with companies.

(6) Involvement of business representatives in the learning process through delivering thematic lectures within the students' subjects and training programmes.

(7) Support from enterprise managers in the process of organising pre-diploma professional practices for University students and participating in the mentoring process by becoming company tutors.

(8) Organisation of joint teams "lecturer - business manager - student" and development of project proposals for solving problems and transferring innovations to a particular company;

(9) Organisation by the University with support from business representatives of activities and events for career orientation and professional development of graduates, such as "Employer evenings", etc.

(10) Establishment of a "University-Enterprise" association or co-operation agreement to monitor career development of graduate students and to keep track of their professional performance; 
(11) Joint assessment by the University and business representatives of the employability of university graduates for an enterprise career in accordance with their professional, management and social competences;

All forms are evaluated by five-level Likert-type scale including answers 2 - poor, 3average, 4- good, 5- very good, 6 - excellent.

Current research aim is to evaluate university - industry cooperation for

PICBE $\mid 1055$ encouragement of employability of graduating students from industry's perspective. Specific objectives of research are (1) evaluation of forms of cooperation based on 4 criteria - importance, application, interest for participation and awareness of the forms, (2) comparison of opinions of industrial companies and universities.

Object of research are industrial companies and the subject of research are their attitudes for cooperation encouraging graduating students' employability.

To fulfil the purpose of current research the presented above questionnaire is modified by adding 3 types of questions - 1) 22 new question aiming to evaluate interest for participation and awareness of the forms among companies; 2) questions for identification of respondents - size of company (micro, small, medium-sized, big), sector, contact details and 3) question for evaluation of existing experience in investigated type of cooperation. For first group of questions five level Likert-type scale is applied using same answers: 2 - poor, 3- average, 4- good, 5- very good, 6 - excellent.

Criteria for choice of respondents. The inquiry was implemented in the territory of 4 districts (NUTS 3 level) - 3 in North Central Bulgaria (Ruse, Razgrad and Silistra) and 1 in North East Bulgaria (Targovishte). Organizations, received questionnaire were defined as key employers for the district by methodology of National Employment Agency, which uses for evaluation criteria as number of announced new jobs last 3 years, financial state of company and potential for future recruitment of students, graduating specialties in professional field "Administration and management" and "General engineering".

Inquiry was distributed among 166 potential employers, 133 responses were received, from which 77 from industrial companies and 56 from other type of organizations. The data shows that in small rural municipalities' jobs for university graduates are provided predominantly by structures of public administration whereas the industrial companies operate in big municipalities.

Continuation for the research. The period set for the research is as follows: JuneNovember 2015.

The hypothesis of research are defined as follows:

Industrial companies evaluate the importance of forms of cooperation between 3 (average)and 4 (good) using five level Likert-type scale;

Industrial companies evaluate importance and application of forms of cooperation lower than universities;

Industrial companies evaluate the application of forms of cooperation with grade 2 (poor) using five level Likert-type scale;

Interest for participation among industrial companies is low with grades between 2 (poor) and 3 (average).

Awareness of the forms among industrial companies is evaluated as 3 (average). 
The comparison between opinions of universities and industrial companies can provide a broader picture about existing gaps and possible effective solutions, which can boost their cooperation.

Methodology for data processing.

For analysis of the result interpretation is applied SPSS software aiming to determine presence of statistically significant differences in responses of respondents by comparing average values. The received responses are used for comparison between opinion of industrial companies and universities.

A hypothesis test for the difference between two means of two independent samples(two-sample t-test) is applied for comparison of opinions of universities and industrial companies.

Pareto analysis is applied for definition of most important, most applied, most interesting and most recognized forms of cooperation from industry point of view.

\section{Conclusion}

Universities are facing challenges to reach compliance with employers' requirements for provision of highly qualified and adaptive candidates. There are many aspects of this problem- readiness of university for change in curricula, development of transferable skills and active partnership with industry. The stakeholders in this process are university, providing education, industrial companies as employers, students who aim to obtain satisfying job and government as external agent, creating all necessary preconditions for transition to work. First 3 have direct interaction, as forth creates environment in which other operate.

The paper proposes a conceptual model for management of transition from university to work, which uses terms "external" and "internal" environment for description of factors influencing on transition. It is estimated that external and internal (subjective) components of the environment are influencing on transition. External components can be differentiated by use of STEP analysis. Categories human capital, social capital and culture capital can be applied for evaluation of internal factors, as their assessment is individual, not in group.

After analysis of the model one can conclude that transition depends on preparation for it during the period in education. Other variable influencing transition are supply and demand on labour market and personal individual characteristics. Consequently universities can influence on employability and thus transition through appropriate preparation of students implemented in partnership with industrial companies.

There is variety of form of cooperation between university and business.Forms can be grouped according their target - cooperation for professional knowledge and skills, career guidance and orientation, management of career realisation of students or cooperation for acquiring complex knowledge and skills.

Representatives of industrial companies in Bulgaria do not have active role for encouragement of transition from university to work. The changes in legislation require more active response from universities, definition of roles and benefits of the stakeholders and development of strategy for cooperation development. 
The proposed questionnaire and methodology for implementation of research and data analysis can provide sound information for managerial decisions which approach shall university follow in order to attract more industrial companies in cooperation.

\section{References}

Afonso, A.Ramírez, J. J.\&Díaz-Puente, J. M. (2012). University-industry cooperation in the education domain to foster competitiveness and employment. Procedia-Social and Behavioral Sciences, 46, 3947-3953

Allan J (1996) Learning outcomes in higher education.Studies in Higher Education 21 93-108.

Andrews, J. and Higson, H. (2008). Graduate employability, 'soft skills' versus 'hard' business knowledge: A European study. Higher education in Europe, 33(4), pp.411-422.

Balta, M., CoughlanJ., Hobson, P. Motivations and barriers in undergraduate students' decisions to enroll in placement courses in the UK, Journal of International Education Research Fourth Quarter 2012 Volume 8, Number 4, p.399 -414

Bennett, N., Dunne, E. and Carre, C. (1999) Patterns of core and generic skill provision in higher education. Higher Education, 37(1), 71-93

Bowles, S.(1972), Schooling and Inequality from Generation to Generation. Journal of Political Economy, vol. 80, N 3, p. 235

Crecente-Romero, F., Giménez-Baldazo, M., Rivera-Galicia, L.F. (2018). Can entrepreneurship channel overqualification in young university graduates in the European Union? Journal of Business Research, Retrieved from https://doi.org/10.1016/j.jbusres.2018.01.056

Decree No. 328 of the Council of Ministers of 30 Nov. 2015, (2015). Retrieved from http://dv.parliament.bg/DVWeb/showMaterialDV.jsp;jsessionid=8E79052685D5EA6 8293EA3E0B7AF96BF?idMat=99137

Deloitte (2013). First steps into the labour market, International survey of students and graduates Central Europe 2013, Retrieved from http://www2.deloitte.com/content/dam/Deloitte/global/Documents/AboutDeloitte/dttl-cei-firststeps2013-web-v03.pdf

Deloitte (2015). First steps into the labour market, International survey of students and graduates Central Europe 2015, Retrieved from https://www2.deloitte.com/content/dam /Deloitte/global/Documents/AboutDeloitte/central-europe/ce_first_steps_2015.pdf

Dima, A.M., Ghinea, V.M., A model of academic leadership, Proceedings of the 12th European Conference on Management Leadership and Governance, 10-11 november 2016, Retrieved from http://www.academic-conferences.org/conferences/ecmlg/,

Dimitrova, I. (2012). Transition from university to work - essence, main problems and perspectives for Bulgaria,PhD thesys, unpublished,Retrieved from https://www.google.bg/url?sa=t\&rct=j\&q=\&esrc=s\&source=web\&cd=2\&cad=rja\&uact $=8 \& v e d=0$ ahUKEwjpreW130TZAhXI1iwKHbYIAVsQFggvMAE\&url=http $\% 3 \mathrm{~A} \% 2 \mathrm{~F} \% 2 \mathrm{~F}$ konkursi.unwe.bg\%2Fdocuments\%2F112Avtoreferat\%2520Irina\%2520Dimitrova.pdf \&usg=AOvVaw3eQ-2gQm0MLl-Waun5SzBU

Ferrer-Balas, D., Buckland, H., de Mingo, M. (2009), Explorations on the University's role in society for sustainable development through a systems transition approach. Case-study of the Technical University of Catalonia (UPC), Journal of Cleaner Production 17 10751085

Ghinea, V.M., Dima, A.M. and Hadad, S., 2017. Excellence Model for Sustainable Convergence in the EU Higher Education. Amfiteatru Economic, 19 (Special No. 11), pp. 1107-1122.

Ghinea, V.M., Moroianu, MR, HR strategy - necessity or fad for business sustainability?,Management\&Marketing. Challenges for the Knowledge economy, vol.11/no.2, 2016, pp. 458-469, ISSN 1842-0206 
Heckman, J. J.\&Kautz, T. (2012). Hard evidence on soft skills. Labour economics, 19(4), 451464.

Herrington A.; Herrington, J. (2004). University to Work Transition: Implications for the Evaluation and Design of Online Communities of Pactice. In R. Atkinson, C. McBeath, D. Jonas-Dwyer \& R. Phillips (Eds), Beyond the Comfort Zone: Proceedings of the 21st ASCILITE Conference Perth, 5-8 December, 379-386. http://www.ascilite.org.au/conferences/perth04/procs/herrington.html.

PICBE |1058

Kanev, M. (2006). In focus- university activity. Reference point - the market, Retrieved from: http://www.uni-svishtov.bg/dialog_old/2006/3.06.M.Kanev.pdf

McLoughlin, C., Luca, J. (2002). A learner-centred approach to developing team skills through web-based learning and assessment, British Journal of Educational Technology Vol 33 No 5, 2002

Naydenov, N.,Yordanova, D.,Kolev, N.,Petkov, A.,Trifonov, E. (2016). Methodology for study of the problems of cooperation "universities - enterprises" in order to increase student's employability, Proceedings from International conference "Leadership and organizational development" (2016), p. 695-702. Retrieved from: http://presssu.com/public_ftp/incoming/62/992/BookPapers_LOD_2016.pdf

NEEA (2016). Criteria system for institutional accreditation of higher schools, adopted by the Accreditation Council to NEAA on 20.10.2016, Retrieved from https://www.neaa.government.bg/images/Criteria_EN/Kriterii_IA_EN.pdf

Oliver R.,McLoughlin C., (2000). Web-based learning and generic skills development UniServe

Rumberger, R.W. The growing Imbalance between Education and Work, The Phi Delta Kappan, Vol. 65, No. 5.1984 , pp. 342-346

Yordanova, D. (2013). Stakeholders in the process of transition between university and employment, НаучнитрудовенаРусенскияуниверситет- 2013, том 52, серия 5.1, Pусе, 2013, стр. 182-186, Retrieved from http://conf.uniruse.bg/bg/docs/cp13/5.1/5.1-31.pdf 